\title{
Sürdürülebilirlik için GİA ve AHP Yöntemleri ile Yeşil Tedarikçi Seçimi: Bir Otomotiv Ana Sanayi Uygulaması
}

\author{
Sedef Kılınç ${ }^{1}$, Betül Yağmahan ${ }^{2 *}$ \\ ${ }^{1}$ Bursa Uludağ Üniversitesi, Mühendislik Fakültesi, Endüstri Mühendisliği Bölümü, Bursa, Türkiye, (ORCID: 0000-0002-6292-7480), sedefcaglan@gmail.com \\ 2* Bursa Uludağ Üniversitesi, Mühendislik Fakültesi, Endüstri Mühendisliği Bölümü, Bursa, Türkiye (ORCID: 0000-0003-1744-3062), betul@uludag.edu.tr
}

(İlk Geliş Tarihi 8 Nisan 2021 ve Kabul Tarihi 11 Ekim 2021)

(DOI: $10.31590 /$ ejosat.909253)

ATIF/REFERENCE: Kılınç, S. \& Yağmahan, B. (2021). Sürdürülebilirlik için GİA ve AHP Yöntemleri ile Yeşil Tedarikçi Seçimi: Bir Otomotiv Ana Sanayi Uygulamas1. Avrupa Bilim ve Teknoloji Dergisi, (27), 686-698.

\section{$\ddot{O} \mathbf{z}$}

Artan rekabet koşulları ve küreselleşmenin etkisiyle son yıllarda işletmeler için tedarikçi seçim kararı, tedarik zincirlerini geliştirmeleri açısından oldukça önemlidir. Bu karar için, tedarikçi değerlendirme kriterlerinin doğru belirlenmesi ve bu kriterlere göre en uygun tedarikçinin seçilmesi gereklidir. Yaşadığımız doğal felaketler çevre bilincini artırmış ve yaşam döngüsü bakış açısını geliştirmiştir. Bu nedenle sürdürülebilirlik için tedarikçi seçiminde yeşil olma kriteri çok kritik bir rol almaktadır. Bu çalışmada, klasik tedarikçi seçim kriterleri ile birlikte çevresel performans kriterlerininde dikkate alındığı yeşil tedarikçi seçim problemi ele alınmıştır. Bu problemin çözümü için çok kriterli karar verme yöntemlerinden Gri İlişkisel Analiz (GİA) ve Analitik Hiyerarşi Prosesi (AHP) kullanılmıştır. Bir otomotiv ana sanayi işletmesine ait tedarikçi seçimi probleminin çözümü için önerilen yöntemler kullanılmış ve elde edilen sonuçlar karşılaştırılmıştır. Ayrıca yeşil tedarikçi seçim sürecinde kullanılan ana kriterler ve karar vericiler kümesinin değişimindeki etkiyi görmek üzere farklı senaryolar üzerinde duyarlılık analizi gerçekleştirilmiştir. Böylece otomotiv endüstrisi yöneticilerine en uygun tedarikçileri seçebilmelerinde yeşil olma kriterini de içeren yararlı bir metodoloji sunulmuştur.

Anahtar Kelimeler: Yeşil tedarikçi seçimi, Gri ilişkisel analiz, Analitik hiyerarşi prosesi, Sürdürülebilirlik, Otomotiv sektörü, Duyarlılık analizi.

\section{Green Supplier Selection Using GRA and AHP Methods for Sustainability: An Automotive Industry Case Study}

\begin{abstract}
In recent years, supplier selection has become very important for companies to improve the supply chain with the impact of increasing competition and globalization. It is necessary to determine the right criteria in supplier selection. Natural disasters have increased environmental awareness and developed a life-cycle perspective. Therefore, green criteria play a very critical role in supplier selection for sustainability. In this study, the green supplier selection problem, in which environmental criteria are taken into account along with the classical supplier selection criteria, is discussed. Grey Relational Analysis (GRA) and Analytical Hierarchy Process (AHP), which are multi-criteria decision-making methods, are used to solve this problem. The proposed methods are applied to solve the supplier selection problem in an automotive industry company, and the obtained results are compared. Also, a sensitivity analysis is carried out on different scenarios to assess the effects of the main criteria and decision-makers used in the green supplier selection process. Hence, a useful methodology considering the green criteria is presented to the managers of the automotive industry for selecting the most suitable suppliers.
\end{abstract}

Keywords: Green supplier selection, Grey relational analysis, Analytical hierarchy process, Sustainability, Automotive industry, Sensitivity analysis.

* Sorumlu Yazar: betul@uludag.edu.tr 


\section{Giriş}

İşletmelerin varlığını sürdürebilmeleri için harcamalarını kontrol altında tutarak performanslarını artırmaları gerekmektedir. İşletmelerin performansını artırmaları sadece kendi çalışmalarına bağlı değildir. Aynı zamanda tedarikçilerinin performanslarıyla da ilişkilidir. Bu nedenle işletmelerin satın alma birimlerinin doğru tedarikçi seçimi yapmaları çok önemli hale gelmektedir. Bir işletmenin ihtiyaçlarını sürekli ve kabul edilebilir bir maliyetle karşılama potansiyeli en yüksek olan tedarikçilerini belirlemek tedarikçi seçiminin amacıdır (Kahraman vd., 2003).

Klasik tedarikçi seçiminde genellikle fiyat, ürün kalitesi, teslimat, finansal ölçüler, teknik işbirliği, şirket yapıları, kalite sistemleri, tedarikçi tecrübesi ve itibarı gibi maliyet ve sosyal odaklı kriterler kullanılmaktadır (Dweiri vd., 2016). Ancak son yıllarda, uluslararası gündemin ilk konularından birisini iklim değişikliğine karşı mücadele oluşturmaktadır. İklim değişikliğinin temel nedeni, insan faaliyetlerine bağlı sera gazları emisyonu olarak belirlenmiştir. Kyota protokolü bu amaçla hazırlanmış, hem sanayileşmiş hem de gelişmekte olan ülkeleri ilgilendiren ve küresel ölçekte sera gazı emisyonlarını azaltmayı amaçlayan bir girişimdir. Böylece uluslararası toplumun bu konudaki artan ilgisiyle de birlikte, tüketici davranışı değişmeye başlamıştır ve satın alınan ürün ve hizmetlerin çevresel etkileri değerlendirilmektedir (Montoya-Torres vd., 2015). Bu nedenle çevresel etkiyi azaltarak ekonomik ve sosyal gelişmeyi sağlamak şeklinde tanımlanan sürdürülebilirlik kavramının gereği olarak tedarikçi seçiminde de maliyet ve sosyal kriterlerin yanında çevresel kriterlerin dikkate alınması gerekmektedir.

Otomotiv sektörü ekonomik olarak büyük ihracat yüzdesine sahip olması, teknolojik gelişmelere yön vermesi, istihdam yaratması, plastik, metal, cam vb. birçok sektörden girdi sağlaması açısından önemli sektörlerin başında gelmektedir. Bununla birlikte, otomotiv sektörü, sera gazı emisyonu salınımında büyük bir paya sahiptir. Sera gazı emisyonu salınım değerlerine bakıldığında, ulaşım ve endüstriyel faaliyetlerin payı sırasıyla \%21 ve \%14 iken, dolaylı $\mathrm{CO}_{2}$ emisyonları açısından bu pay $\% 0,3$ ve $\% 11$ değerindedir (IPCC, 2014). Bu nedenle bu sektörün ürünlerinde, üretim ve tedarik faaliyetlerinde çevresel sürdürülebilirliği sağlaması büyük önem arz etmektedir. $\mathrm{Bu}$ amaçla, işletmeler yeşil üretim faaliyetlerini benimsemektedirler. Örneğin daha az ambalaj kullanan, kirliliği azaltan ve/veya enerji tüketimini azaltan ürünler/hizmetler geliştirerek çevresel korumayı sağlamaya çalışmaktadırlar (Humphreys vd., 2003). Diğer yandan yeşil tedarik zinciri bu açıdan benimsenen bir strateji olmaktadır. İşletmelerin kendi çevresel etkilerinin yanında yaşam döngüsü bakış açısıyla tedarikçilerinin de çevresel etkilerini göz önüne alması önemlidir.

Yeşil tedarik zinciri kararlarının başında ise tedarikçi seçimi gelmektedir. Yeşil tedarikçi seçimi, klasik yöntem ile tedarikçi seçiminden farklı olarak, kriterlerin arasına yeşil parametresinin de eklenmesidir (Genovese vd., 2013). Literatürde yeşil tedarik sürecinde çevresel faktörlerin önemini vurgulayan ve dikkate alınması gereken unsurları belirleyen çalışmalar yapılmıştır (Kumar vd., 2012; Igarashi vd., 2013). Yeşil tedarik yaklaşımı müşteriler, yasalar ve düzenlemelerle uyumlu olmalıdır ve bir tedarikçinin yeşil tedarik zincirinde bir ortak olarak uygunluğunu belirlemesi için yeşil tedarikçi değerlendirme sistemi gereklidir (Lee vd., 2009).
Literatürde tedarikçi seçimi problemi ile ilgili oldukça kapsamlı çalışmalar bulunmasına rağmen, yeşil tedarikçi seçimi ise ilgili çalışmaların sınırlı olduğu görülmektedir (Shen vd., 2013; Wang Chen vd., 2016; Haeri ve Rezaei, 2019). Yeşil tedarikçi seçimi probleminin çözümü ile ilgili az sayıda da olsa optimizasyon yaklaşımları önerilmiştir. Bu çalışmaların birçoğu tedarikçi seçimi problemini de içeren tedarik zinciri optimizasyonu kapsamında farklı problemlerin bir arada ele alındığı çalışmalardır. Tsai ve Hung (2009), yeşil tedarikçi seçimi ve akış atama problemlerini içeren yeşil tedarik zinciri yapısının optimizasyonu için bir bulanık hedef programlama yöntemi önermişlerdir. Kannan vd. (2013), yeşil tedarikçi belirleme ve sipariş atama problemi için entegre bir çözüm yaklaşımı önermişlerdir. Öncelikle bulanık Analitik Hiyerarşi Prosesi (AHP) yöntemi ile kriter ağırlıkları belirlenmiş, tedarikçilerin seçimi ise bulanık TOPSIS yöntemi kullanılarak gerçekleştirilmiştir. Son olarak bulanık çok-amaçlı doğrusal programlama modeli ile herbir tedarikçiye ait sipariş büyüklüğü ataması yapılmıştır. Jain vd. (2016) entegre bir karar destek süreci önermişlerdir. İlk aşamada önerdikleri doğrusal programlama modeli, karbon piyasasını dikkate alan bir karbon ticareti modelidir. İkinci aşamada yeşil tedarikçi seçim süreci için, önerilen karbon ticareti modelinin çıktılarını girdi olarak kullanan veri zarflama analizi modeli geliştirilmiştir. Hamdan ve Cheaitou (2017), çok-amaçlı tamsayılı doğrusal programlama modeli önermişlerdir. Önerilen model en iyi tedarikçileri ve onlara olan sipariş miktarlarını belirlemektedir. Model girdi olarak iki veri kullanmaktadır. İlki, bulanık TOPSIS yöntemi ile elde edilen geleneksel ve yeşil kriterlere göre tedarikçi ağırlıklarıdır. Diğeri ise AHP yöntemi kullanılarak organizasyon stratejisine göre hesaplanan kriter ağırlıklarıdır. Babbar ve Amin (2018), yeşil tedarikçi seçimi ve sipariş büyüklüğü belirleme problemi için iki aşamalı bir çözüm yaklaşımı önermişleridir. İlk aşama da tedarikçiler QFD modeline göre değerlendirilmektedir. İkinci aşamada ise sipariş büyüklüğünü bulmak için ilk aşamanın sonuçlarını kullanan bir çok-amaçlı optimizasyon modeli önerilmiştir.

Yeşil tedarikçi seçimi probleminin çözümü için bir diğer çözüm yaklaşım grubu ise sezgisel ve yapay zeka yaklaşımlarıdır. $\mathrm{Bu}$ çözüm yaklaşımlarını kullanan yine sınırlı sayıda çalışma bulunmaktadır. Kuo vd. (2010), yapay sinir ağları yöntemi ile iki çok nitelikli karar analizi (multi-attribute decision analysis) yöntemini entegre ederek bu problem için yeni bir yaklaşım önermişlerdir. Yeh ve Chuang (2011), yeşil tedarik zincirinde yeşil tedarikçi seçimi için öncelikle maliyet, zaman, ürün kalitesi ve yeşil değerlendirme kriterlerini içeren çok-amaçlı karışıktamsayılı doğrusal olmayan programlama modeli geliştirmişlerdir. Daha sonra bu çelişkili amaçlar için paretooptimal çözümler kümesini bulmak üzere çok-amaçlı genetik algoritma yaklaşımı önermişlerdir. Fallahpour vd. (2016) bu problem için veri zarflama analizi ve genetik programlama yaklaşımlarını birarada kullanarak çözüm elde etmişlerdir.

Yeşil tedarikçi seçim problemi, birbiriyle çelişkili nitel ve nicel kriterleri içeren tipik çok kriterli bir karar verme (ÇKKV) problemidir. $\mathrm{Bu}$ nedenle bu problem için literatürde sıklıkla ÇKKV yöntemleri önerilmiştir. Literatürde bu konuyla ilgili yapılan çalışmalar, yıl bazında kullanılan yöntemleri ve uygulamalarının gerçekleştirildiği sektörleri de içerecek şekilde Tablo 1'de özetlenmiştir. 2015 y1lı öncesini içeren kapsamlı bir derleme çalışması Govindan vd. (2015) tarafından yapılmıştır. 
Avrupa Bilim ve Teknoloji Dergisi

Tablo 1. ÇKKV yöntemleri kullanan yeşil tedarikçi seçimi çalışmaları

\begin{tabular}{|c|c|c|c|}
\hline Yazar(lar) & Yil & Yöntem* & Sektör \\
\hline Lu vd. (2007) & 2007 & AHP & Elektronik \\
\hline Lee vd. (2009) & 2009 & Fuzzy AHP & Elektronik \\
\hline Tuzkaya vd. (2009) & 2009 & Fuzzy ANP + Fuzzy PROMETHEE & Elektronik \\
\hline Grisi vd. (2010) & 2010 & Fuzzy AHP & Sayısal Uygulama \\
\hline Büyüközkan (2012) & 2012 & Fuzzy AHP; Fuzzy AD & Otomotiv \\
\hline Roshandel vd. (2013) & 2013 & Fuzzy TOPSIS & Kimya \\
\hline Hsu vd. (2013) & 2013 & DEMATEL & Elektronik \\
\hline Hashemi vd. (2014) & 2014 & GİA & Sayısal Uygulama \\
\hline Tsui ve Wen (2014) & 2014 & AHP + ELECTRE III & Elektronik \\
\hline Kannan vd. (2014) & 2014 & Fuzzy TOPSIS & Elektronik \\
\hline Hashemi vd. (2015) & 2015 & ANP; GİA & Otomotiv \\
\hline Cao vd. (2015) & 2015 & Fuzzy TOPSIS & Otomotiv \\
\hline Kannan vd. (2015) & 2015 & Fuzzy AD & Plastik \\
\hline Şişman (2016) & 2016 & Bulanık MOORA & Elektronik \\
\hline Wang Chen vd. (2016) & 2016 & Fuzzy AHP; Fuzzy TOPSIS & Elektronik \\
\hline Awasthi ve Kannan (2016) & 2016 & Fuzzy NGT + VIKOR & Otomotiv \\
\hline Yazdani vd. (2017) & 2017 & $\begin{array}{l}\text { DEMATEL + COPRAS; } \\
\text { DEMATEL + MOORA }\end{array}$ & Gida \\
\hline Qin vd. (2017) & 2017 & TODIM+IT2FSs & Otomotiv \\
\hline Govindan vd. (2017) & 2017 & PROMETHEE & Gida \\
\hline Gupta ve Barua (2017) & 2017 & BWM + Fuzzy TOPSIS & Otomotiv \\
\hline Banaeian vd. (2018) & 2018 & $\begin{array}{l}\text { Fuzzy TOPSIS; Fuzzy VIKOR; Fuzzy } \\
\text { GİA }\end{array}$ & Gida \\
\hline Haeri ve Rezaei (2019) & 2019 & GİA & Otomotiv \\
\hline Gupta vd. (2019) & 2019 & $\begin{array}{l}\text { Fuzzy AHP + MABAC; } \\
\text { Fuzzy AHP + WASPAS; } \\
\text { Fuzzy AHP + TOPSIS }\end{array}$ & Otomotiv \\
\hline Wan vd. (2020) & 2020 & Fuzzy PROMETHEE & Gida \\
\hline
\end{tabular}

*ANP: Analitik Ağ Süreci (Analytic Network Process); AD: Aksiyomatik Tasarım (Axiomatic Design); NGT: Nominal Grup Tekniği (Nominal Group Technique); BWM: Best Worst Yöntemi; IT2FSs: Aralık Tip-2 Fuzzy Kümeleri (Interval Type-2 Fuzzy Sets) 
Gri ilişkisel analiz (GİA), gri sistem teorisinin bir parçasıdır ve birçok faktör ve değişken arasında karmaşık ilişkilerin olduğu problemleri çözmek için uygun bir yöntemdir (Kuo vd., 2008). Gri sistem teorisinin en büyük avantajlarından biri, nispeten az miktarda veri kullanarak ve faktörlerde büyük değişkenlikle tatmin edici sonuçlar üretebilmesidir (Yang ve Chen, 2006). Daha belirsiz ortamlarda karar vermeye uygundur (Pitchipoo vd., 2015). Hem nicel hem de nitel özelliklerin değerlendirilmesini içerdiğinden tedarikçi seçim probleminde ek bir avantaja sahiptir (Rajesh ve Ravi, 2015).

Bu çalışmada, yeşil tedarikçi seçim problemi için literatürde yaygın olarak kullanılan ÇKKV yöntemlerinden GİA ve AHP yöntemleri kullanılmıştır. Ayrıca, bir otomotiv ana sanayi işletmesinin yeşil tedarik zinciri optimizasyonuna destek olmak üzere yeşil tedarikçi seçimi gerçekleştirilmiştir. Kullanılan yöntemler ile elde edilen sonuçlar karşılaştırılmıştır. Ayrıca karar vericilerin amaçlarına ve ana kriterlere bağlı olarak sonuçlardaki değişimin etkisini görmek üzere farklı senaryolar üzerinde duyarlılık analizi yapılmıştır. Bu çalışmanın katkıları şöyle özetlenebilir:

(i) Sürdürülebilirlik kriterleri dikkate alınarak önerilen GİA ve AHP yöntemleri ile tedarikçi seçimi gerçekleştirilmiştir.

(ii) Problemin farklı kriter seçenekleri ve ağırlıkları içermesi durumunda çözüme olan etki duyarlılık analizi ile değerlendirilmiştir. (iii) Önerilen metodoloji, otomotiv sektörünün önde gelen ana sanayi işletmesine ait tedarikçi seçim probleminin çözümü için uygulanmıştır.

Çalışmanın bundan sonraki bölümünde yeşil tedarikçi seçimi problemini çözmek üzere kullanılacak metodoloji tanımlanmıştır. Üçüncü bölümde, otomobil ana sanayi işletmesine ait satın alma sürecinde karşılaşılan yeşil tedarikçi seçim problemi çözüm uygulaması bulunmaktadır. Dördüncü bölümde ise, farklı kriter ve karar verici kümeleri içeren senaryolar üzerinde duyarlılık analizi ile çözümlerdeki etki değerlendirilmiştir. Son olarak ise, elde edilen sonuçlar ve tartışma verilmiştir.

\section{Metodoloji}

Otomotiv ana sanayi işletmesine ait yeşil tedarikçi seçimi için önerilen üç aşamalı metodoloji Şekil 1'de özetlenmiştir. İlk aşamada, problem için uzmanlar, değerlendirme kriterleri ve alternatif tedarikçiler belirlenmelidir. İkinci aşamada, GİA ve AHP yöntemleri ile tedarikçi sıralamaları elde edilir ve kullanılan yöntemlerin sonuçları karşılaştırılır. Son aşamada, farklı senaryolar üzerinde duyarlılık analizi yapılmakta ve karar vericinin nihai seçimi yapması ile süreç tamamlanmaktadır.

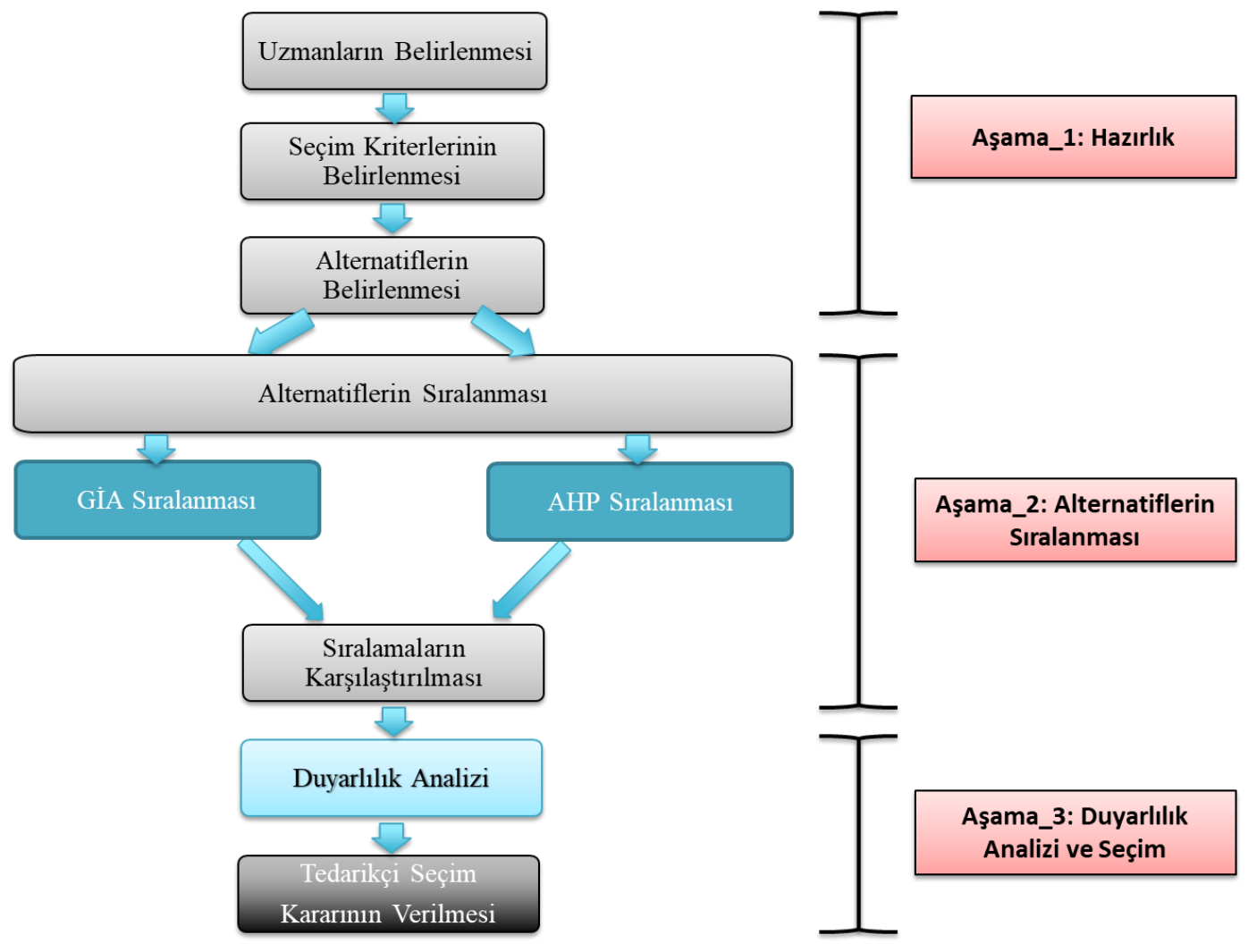

Şekil 1. Önerilen metodolojinin adımları

Gri sistem teorisinde, bilginin düzeyine göre, eğer sistem bilgisi tam olarak biliniyorsa sistem, beyaz sistem olarak adlandirılır; eğer sistem bilgisi bilinmiyorsa bu sisteme, siyah sistem denir.

\subsection{Gri İlişkisel Analiz}

Gri sistem teorisi, ilk defa 1982 yılında Prof. Julong Deng tarafından önerilen fikir ile ortaya çıkmıştır (Liu ve Lin, 2010). e-ISSN: 2148-2683
Bilinen kısmi bilgi ve bilinmeyen kısmi bilgi içeren bir sistem, gri sistemdir (Li vd., 2008). GİA yönteminin uygulama adımları aşağıda özetlenmiştir (Pitchipoo vd., 2015; Wu, 2002; Chan, 2008): 
Adım 1. Referans serilerinin oluşturulması: $X_{o}$ referans serileri, herbir kriter için en büyük değere sahiptir ve denklem 1 ile gösterilir:

$X_{o}=\left(x_{o}(1) x_{o}(2) \ldots x_{o}(n)\right)$

Burada $x_{i}(j)$ değeri, $i$. alternatifin $(i=1,2, \ldots, m) j$. kriterini $(j=$ $1,2, \ldots, n)$ ifade etmektedir. Referans serileri $m \times n$ boyutundaki $X$ kriter matrisi (denklem 2) ile gösterilebilir:

$X=\left[\begin{array}{ccc}x_{1}(1) & x_{1}(2) \cdots & x_{1}(n) \\ x_{2}(1) & x_{2}(2) \cdots & x_{2}(n) \\ \cdots & \cdots & \cdots \\ \cdots & \cdots & \cdots \\ x_{m}(1) & x_{m}(2) & x_{m}(n)\end{array}\right]$

Adım 2. Verilerin normalize edilmesi: Normalizasyon, daha sonraki analizler için verilerin farklı birim ve aralıklara sahip olduğu zaman bunları karşılaştırılabilir bir veriye dönüştürmek için gereklidir. Veriler üç şekilde işlenebilir; yani, daha büyükdaha iyidir, daha küçük-daha iyidir ve ideal değer-en iyisidir.

Veri değerlerinin büyük olması durumunda normalizasyon (denklem 3):

$x_{i}^{*}(j)=\frac{x_{i}(j)-\min _{j} x_{i}(j)}{\max _{j} x_{i}(j)-\min _{j} x_{i}(j)}$

Veri değerlerinin küçük olması durumunda normalizasyon (denklem 4):

$x_{i}^{*}(j)=\frac{\max _{j} x_{i}(j)-x_{i}(j)}{\max _{j} x_{i}(j)-\min _{j} x_{i}(j)}$

İdeal değerin daha en iyi olması durumunda normalizasyon (denklem 5):

$x_{i}^{*}(j)=\frac{\left|x_{i}(j)-x_{0 b}(j)\right|}{\max _{j} x_{i}(j)-x_{0 b}(j)}$

Burada $x_{0 b}(j)$ hedef değerdir ve $\max _{j} x_{i}(j) \geq x_{0 b}(j) \geq$ $\min _{j} x_{i}(j)$ aralı̆̆ında değer alır.

Orjinal veri, bu üç tip veri dönüşümü ile normalleştirildikten sonra $X$ kriter matrisi denklem 6 ile verilen matrise dönüşmektedir:

$X_{i}^{*}=\left[\begin{array}{ccc}x_{1}^{*}(1) & x_{1}^{*}(2) \cdots & x_{1}^{*}(n) \\ x_{2}^{*}(1) & x_{2}^{*}(2) \cdots & x_{2}^{*}(n) \\ \cdots & \cdots & \cdots \\ \cdots & \cdots & \cdots \\ x_{m}^{*}(1) & x_{m}^{*}(2) & x_{m}^{*}(n)\end{array}\right]$

Adım 3. Mutlak değer tablosunun oluşturulması: $j$. kriter için $x_{0}^{*}$ ile $x_{i}^{*}$ arasındaki mutlak fark $\Delta_{0 i}(j)$ denklem 7 ile belirlenir:

$$
\Delta_{0 i}(j)=\left|x_{0}^{*}(j)-x_{i}^{*}(j)\right|
$$

$$
=\left[\begin{array}{cccc}
\Delta_{01}(1) & \Delta_{01}(2) & \cdots & \Delta_{01}(n) \\
\Delta_{02}(1) & \Delta_{02}(2) & \cdots & \Delta_{02}(n) \\
\vdots & \vdots & \ddots & \vdots \\
\Delta_{0 m}(1) & \Delta_{0 m}(2) & \cdots & \Delta_{0 m}(n)
\end{array}\right]
$$

Adım 4. Her bir kriter için gri ilişkisel katsayıların hesaplanması: En iyi ve gerçek sonuçlar arasındaki ilişkiyi ifade etmek için normalleştirilmiş verilerden gri ilişkisel katsayı denklem 8 kullanılarak hesaplanır:

$\gamma_{0 i}(j)=\frac{\Delta \min +\xi \Delta \max }{\Delta_{0 i}(j)+\xi \Delta \max }$

Burada $\Delta \max =\max _{i} \max _{j} \Delta_{0 i}(j), \Delta \min =\min _{i} \min _{j} \Delta_{0 i}(j)$ ve ayırt edici katsayı $\xi \in[0,1]$.

Adım 5. Gri ilişki derecesinin hesaplanması: $i$. alternatif için gri ilişki derecesi, gri ilişki katsayıları toplamanın ortalamasıdır (denklem 9):

$\Gamma_{0 i}=\frac{1}{n} \sum_{j=1}^{n} \gamma_{0 i}(j)$

Eğer kriterler arasında eşit olmayan ağırlıklar söz konusuysa, gri ilişki katsayıları denklem 10 ile belirlenir:

$\Gamma_{0 i}=\sum_{j=1}^{n} \beta_{j} \gamma_{0 i}(j)$

Burada $\beta_{j}, j$. kriterin ağırlığıdır ve $\sum_{j=1}^{n} \beta_{j}=1$.

\subsection{Analitik Hiyararşi Proses}

AHP, Saaty $(1977,1990)$ tarafından geliştirilen bir ÇKKV yaklaşımıdır. AHP yaklaşımı üç adımdan oluşmaktadır (Albayrak ve Erensal, 2004):

Adım 1: Karar hiyerarşisinin oluşturulması

Adım 2: Önceliklendirme süreci

Adım 3: Sonuçların hesaplanması

Adım 1. Karar hiyerarşisinin oluşturulması: AHP ile değerlendirilen problem için amaçlar, kriterler ve alternatifleri içeren bir hiyerarşi oluşturulur. Bir hiyerarşinin dört seviyesi vardır: Birinci seviyede problemin genel amacı, ikinci ve üçüncü seviyede ana ve alt kriterler, son seviyede ise karar alternatifleri bulunur (Albayrak ve Erensal, 2004).

Adım 2. Önceliklendirme süreci: $\mathrm{Bu}$ adımda hiyerarşinin her seviyesinde, kriterler ve alt kriterlerin kendi aralarındaki önem derecelerinin belirlenmesi için ikili olarak karşılaştırılarak ikili karşılaştırma karar matrisleri oluşturulur. $n$ kriter için ikili karşılaştırma karar matrisi $A$, denklem 11 ile gösterilebilir (Dağdeviren, 2008):

$A=\left[\begin{array}{cccc}a_{11} & a_{12} & \cdots & a_{1 n} \\ a_{21} & a_{22} & \cdots & a_{2 n} \\ \vdots & \vdots & \ddots & \vdots \\ a_{n 1} & a_{n 2} & \cdots & a_{n n}\end{array}\right]$, 
$a_{i i}=1, a_{j i}=1 / a_{i j}, a_{i j} \neq 0$

Burada $a_{i j}(i, j=1,2, \ldots, n)$ ikili karşılaştırma değerini ifade eder.

Adım 3. Sonuçların hesaplanması: Bu aşamada ilk olarak kriterler için ağırlıklar hesaplanmaktadır. Ağırlıklar, ikili karşılaştırma matrisinin en büyük özdeğerine $\left(\lambda_{\max }\right)$ karşılık gelen normalize edilmiş ağırlık vektörü $(w)$ tarafından denklem 12 sağlanacak şekilde belirlenmektedir (Albayrak ve Erensal, 2004):

$A w=\lambda_{\max } w$

Karar vericilerin kriter karşılaştırması yaparken tutarsızlıkları oluşabilir. Bir karşılaştırma matrisinin tutarlı olup olmadığını hesaplamak için tutarlılık oranı kullanılır. Karşılaştırma matrisinin tutarlılığını belirlemek için denklem 13 ile hesaplanan tutarlılık oranı (CR) kullanılır (Saaty, 1990):

$C R=C I / R I$

Burada $C I$, tutarlılık göstergesini, $R I$ ise rassallık göstergesinin ifade etmektedir ve kriter sayısına göre değeri belirlenir. $C I$ değeri ise denklem 14 ile hesaplanmaktadır:

$C I=\frac{\lambda_{\max }-n}{n-1}$

Tutarlılık oranı $(C R), 0,10$ 'un altında ise yapılan karşılaştırmanın tutarlı olduğu söylenir.

\section{Yeşil Tedarikçi Seçimi Uygulaması}

Her sektör dalında, işletmelerin karlı büyümeleri, başarı sağlamaları ve elde ettikleri başarıları sürdürebilir hale getirmelerinde tedarikçilerinin payı çok yüksektir. Özellikle otomotiv sektöründe, çok farklı yapıda ve sayıda malzemeye ihtiyaç duyulduğu için çok fazla sayıda da tedarikçiye ihtiyaç duyulmaktadır. Otomotiv işletmeleri yeni üretimine başladığı bir model seri üretimine uzunca bir süre devam ettiği için, istenilen kriterlere uygun doğru tedarikçi ile uzun yıllar çalışılması çok önemlidir. Bu nedenle işletmelerin proje dönemlerinde tedarikçi seçerken kriterlerini sürecin en başında ve önceliklerine göre doğru şekilde belirlemeleri gerekmektedir. Sonrasında alternatifler arasından seçilen kriterlere göre işbirliği kuracakları tedarikçileri belirlemeleri gerekmektedir.

$\mathrm{Bu}$ çalışma kapsamında, otomotiv sektöründeki bir ana sanayi işletmesinde otomobilin ana iskeletini oluşturan ve yolcunun güvenliği için önem taşıyan sac parçaların üretimini sağlayacak tedarikçinin seçimi gerçekleştirilmiştir. $\mathrm{Bu}$ amaçla öncelikle uygulamanın gerçekleştirildiği ana sanayi işletmesinin satın alma departmanı çalışanları ve yöneticilerden oluşan toplam on kişilik $\left(E_{1}, E_{2}, E_{3}, \quad E_{4}, E_{5}, E_{6}, E_{7}, E_{8}, E_{9}, E_{10}\right)$ uzman grubu oluşturulmuş ve süreç boyunca bu kişilerin bilgilerine başvurulmuştur.

Uygulamada toplam altı tedarikçi $\left(A_{1}, A_{2}, A_{3}, A_{4}, A_{5}, A_{6}\right)$, ana kriterler $\left(K_{1}, K_{2}, K_{3}, K_{8}, K_{9}, K_{10}\right)$ ve alt kriterler $\left(K_{4}, K_{5}, K_{6}, K_{7}\right)$ ile değerlendirilmektedir. Ana kriterden dört tanesi subjektif, üç tanesi ise objektif kriterlerdir. Ana kriterler ve alt kriterler hiyerarşisi Şekil 2'de verilmektedir. Tüm değerlendirme kriterlerinin tanımı Tablo 2'de özetlenmiştir.

\subsection{GİA Yöntemi ile Yeşil Tedarikçi Seçimi}

GİA yönteminin birinci adımına göre referans serisi oluşturabilmek için öncelikle uzmanlar grubuna tedarikçilerin subjektif kriterlerin göre değerlendirilmesi için anket uygulanmıştır. Objektif kriterlerin değerleri ise gerçek verilere dayanan bilgilerden alınmıştır. Uzmanların anketi cevaplama sürecinde subjektif kriterleri değerlendirilmesinde Tablo 3'deki gri sayı skalası kullanılmıştır. Objektif kriterler ise Tablo 4'de verilen skalaya göre puanlanmıştır. Uzmanların subjektif kriterlere göre değerlendirme sonuçları Tablo 5'de ve objektif kriterlere göre değerlendirilme sonuçları Tablo 6'da verilmiştir. Elde edilen veriler kullanılarak referans serisi oluşturulmuş ve yöntemin ikinci adımına göre bu değerler normalize edilmiştir. Normalizasyon değerleri Tablo 7'de görülmektedir.

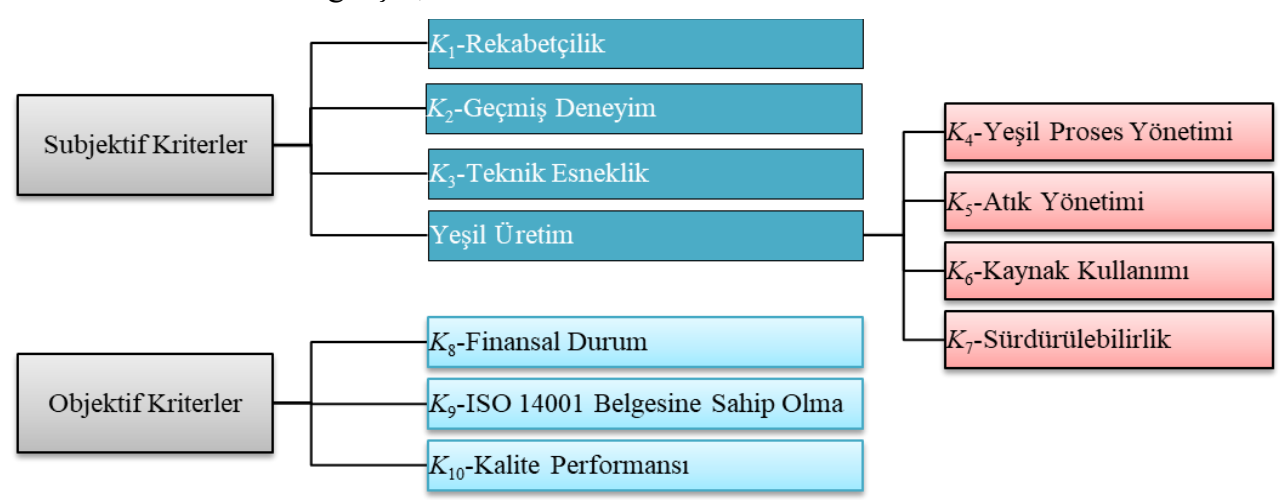

Şekil 2. Ana ve alt kriterler 
Tablo 2. Yeşil tedarikçi seçimi kriter tanımları

\begin{tabular}{|c|c|c|}
\hline Kriter no & Kriter ad 1 & Tanım \\
\hline$K_{1}$ & Rekabetçilik & En düşük fiyatı sağlama ve uzun vadede en çok indirim oranını verme \\
\hline$K_{2}$ & Geçmiş deneyim & $\begin{array}{l}\text { Tedarikçilerle uzun yıllardır çalışmasıyla oluşan geçmiş deneyimleri, o } \\
\text { işletme ile yaşanan tecrübeler }\end{array}$ \\
\hline$K_{3}$ & Teknik esneklik & $\begin{array}{l}\text { Satın alma yapılacak malzemenin, tedarikçinin bu malzemeyi } \\
\text { yapabilirliği, uygun üretim hatlarının olması ve o parçayla ilgili } \\
\text { tecrübeleri }\end{array}$ \\
\hline$K_{4}$ & Yeşil proses yönetimi & $\begin{array}{l}\text { Çevre üzerindeki doğrudan etkilerinin yanı sıra değer zincirinin } \\
\text { bütününde oluşan dolaylı çevresel etkilerin de kontrol altına alması ve } \\
\text { mümkün olan en düşük seviyeye çekmesi }\end{array}$ \\
\hline$K_{5}$ & Atık yönetimi & $\begin{array}{l}\text { Faaliyetlerinden kaynaklanan atıkları kaynağında azaltması ve mümkün } \\
\text { olduğunca atıkların geri kazanılması. Malzeme kullanımının azaltılması } \\
\text { geri dönüştürülmüş ve geri dönüştürülebilir malzeme kullanımı ve oluşan } \\
\text { atıkların tamamının geri kazanılmasına yönelik çalıșılması }\end{array}$ \\
\hline$K_{6}$ & Kaynak kullanımı & $\begin{array}{l}\text { Ekosistemin devamlılı̆̆ için doğal kaynakların kendini yenileme } \\
\text { kapasitesini korumak amacıyla sorumlu kaynak kullanımı. Yenilenebilin } \\
\text { enerji kullanımı, verimli su tüketimi ve atıkların geri kazanımı ile çevrese } \\
\text { etkilerin azaltılması }\end{array}$ \\
\hline$K_{7}$ & Sürdürülebilirlik & $\begin{array}{l}\text { Sürdürülebilir kalkınma yaklaşımı çerçevesinde, ekonomik, çevresel ve } \\
\text { toplumsal boyutlarıyla bugünden geleceğe uyumlu bir planlama yapılmas }\end{array}$ \\
\hline$K_{8}$ & Finansal durum & $\begin{array}{l}\text { Uzun vadeli kurulan ilişkinin devamlılığ s sağlamak için işletmenin } \\
\text { finansal durumu (İsletmeye yapılan finansal denetim sonucu alınan puan) }\end{array}$ \\
\hline$K_{9}$ & $\begin{array}{l}\text { ISO } 14001 \text { belgesine } \\
\text { sahip olma }\end{array}$ & Tedarikçinin ISO 14001 belgesinin olması durumu \\
\hline$K_{10}$ & Kalite performans 1 & $\begin{array}{l}\text { Tedarikçinin bir y1l boyunca ana sanayiye sevk ettiği parçalardan elde } \\
\text { ettiği kalite puanlarının toplamı }\end{array}$ \\
\hline
\end{tabular}

Tablo 3. Subjektif kriterler için değerlendirme skalası (Li vd., 2008)

\begin{tabular}{lc}
\hline Skala & Gri sayı karşılı̆̆ \\
\hline Çok Zayıf(VP) & {$[0,1]$} \\
Zayıf (P) & {$[1,3]$} \\
Orta Derecede Zayıf (MP) & {$[3,4]$} \\
Ortalama (F) & {$[4,5]$} \\
Orta Derecede İyi (MG) & {$[5,6]$} \\
İyi (G) & {$[6,9]$} \\
Çok İyi (VG) & {$[9,10]$} \\
\hline
\end{tabular}

Tablo 4. Objektif kriterler için değerlendirme skalası

\begin{tabular}{lc}
\hline Kriter & Puan aralı̆̆1 \\
\hline Finansal durum & {$[1,3]$} \\
ISO 14001 belgesine sahip olma & {$[0,1]$} \\
Kalite performans1 & {$[0,100]$} \\
\hline
\end{tabular}

Tablo 5. Subjektif kriterler için uzmanların değerlendirme sonuçları

\begin{tabular}{|c|c|c|c|c|c|c|c|}
\hline Kriter no & Uzmanlar & $A_{1}$ & $A_{2}$ & $A_{3}$ & $A_{4}$ & $A_{5}$ & $A_{6}$ \\
\hline \multirow{11}{*}{$K_{1}$} & $\overline{\bar{E}}$ & $\overline{\bar{G}}$ & $\overline{\mathrm{G}}$ & $\overline{\mathrm{G}}$ & $\overline{\mathrm{G}}$ & MG & $\overline{\mathrm{G}}$ \\
\hline & $E_{2}$ & G & MG & MG & G & VG & $\mathrm{G}$ \\
\hline & $E_{3}$ & $\mathrm{P}$ & $\mathrm{G}$ & $\mathrm{P}$ & G & $\mathrm{P}$ & MG \\
\hline & $E_{4}$ & F & $\mathrm{F}$ & MG & G & F & $\mathrm{G}$ \\
\hline & $E_{5}$ & MG & MG & $\mathrm{F}$ & F & F & MP \\
\hline & $E_{6}$ & MG & MG & G & G & MG & MG \\
\hline & $E_{7}$ & $\mathrm{G}$ & $\mathrm{G}$ & $\mathrm{F}$ & F & MP & $\mathrm{F}$ \\
\hline & $E_{8}$ & VG & G & F & $\mathrm{F}$ & $\mathrm{F}$ & $\mathrm{F}$ \\
\hline & $E_{9}$ & VG & G & MG & MG & MP & MP \\
\hline & $E_{10}$ & G & VG & $\mathrm{F}$ & MG & MG & MP \\
\hline & $E_{1}$ & G & G & G & G & MG & $\mathrm{G}$ \\
\hline
\end{tabular}


European Journal of Science and Technology

\begin{tabular}{|c|c|c|c|c|c|c|c|}
\hline \multirow{9}{*}{$K_{2}$} & $E_{2}$ & $\mathrm{VG}$ & $\mathrm{VG}$ & VG & VG & $\mathrm{G}$ & VG \\
\hline & $E_{3}$ & VP & F & $\mathrm{P}$ & $\mathrm{G}$ & $\mathrm{P}$ & $\mathrm{G}$ \\
\hline & $E_{4}$ & $\mathrm{G}$ & $\mathrm{G}$ & $\mathrm{G}$ & $\mathrm{G}$ & MP & MG \\
\hline & $E_{5}$ & $\mathrm{G}$ & VG & MG & MG & MG & $\mathrm{F}$ \\
\hline & $E_{6}$ & VG & VG & VG & $\mathrm{G}$ & $\mathrm{G}$ & MG \\
\hline & $E_{7}$ & $\mathrm{G}$ & $\mathrm{G}$ & VG & $\mathrm{G}$ & $\mathrm{G}$ & $\mathrm{F}$ \\
\hline & $E_{8}$ & $\mathrm{VG}$ & $\mathrm{G}$ & $\mathrm{VG}$ & $\mathrm{G}$ & $\mathrm{G}$ & $\mathrm{F}$ \\
\hline & $E_{9}$ & VG & $\mathrm{G}$ & $\mathrm{G}$ & $\mathrm{G}$ & $\mathrm{G}$ & MG \\
\hline & $E_{10}$ & $\mathrm{G}$ & VG & $\mathrm{G}$ & VG & $\mathrm{G}$ & MG \\
\hline \multirow{10}{*}{$K_{3}$} & $E_{1}$ & $\mathrm{G}$ & $\mathrm{G}$ & $\mathrm{G}$ & $\mathrm{G}$ & MG & $\mathrm{G}$ \\
\hline & $E_{2}$ & VG & VG & VG & VG & $\mathrm{G}$ & $\mathrm{G}$ \\
\hline & $E_{3}$ & $\mathrm{G}$ & $\mathrm{P}$ & $\mathrm{P}$ & $\mathrm{VG}$ & VP & $\mathrm{P}$ \\
\hline & $E_{4}$ & $\mathrm{G}$ & $\mathrm{G}$ & MG & $\mathrm{F}$ & MP & $\mathrm{F}$ \\
\hline & $E_{5}$ & VG & G & $\mathrm{G}$ & $\mathrm{G}$ & $\mathrm{F}$ & $\mathrm{F}$ \\
\hline & $E_{6}$ & VG & VG & VG & $\mathrm{G}$ & $\mathrm{G}$ & MG \\
\hline & $E_{7}$ & $\mathrm{G}$ & $\mathrm{G}$ & $\mathrm{G}$ & MG & MG & MP \\
\hline & $E_{8}$ & $\mathrm{G}$ & $\mathrm{MG}$ & $\mathrm{MG}$ & $\mathrm{F}$ & $\mathrm{F}$ & $\mathrm{F}$ \\
\hline & $E_{9}$ & $\mathrm{G}$ & MG & $\mathrm{G}$ & MG & F & MP \\
\hline & $E_{10}$ & $\mathrm{G}$ & $\mathrm{G}$ & G & MG & MG & MP \\
\hline \multirow{10}{*}{$K_{4}$} & $E_{1}$ & G & G & G & G & G & $\mathrm{F}$ \\
\hline & $E_{2}$ & $\mathrm{P}$ & $\mathrm{P}$ & $\mathrm{P}$ & $\mathrm{P}$ & $\mathrm{P}$ & $\mathrm{P}$ \\
\hline & $E_{3}$ & F & F & MP & G & $\mathrm{P}$ & $\mathrm{P}$ \\
\hline & $E_{4}$ & $\mathrm{P}$ & MP & $\mathrm{P}$ & $\mathrm{P}$ & $\mathrm{P}$ & $\mathrm{P}$ \\
\hline & $E_{5}$ & MG & MG & F & MG & MG & $\mathrm{F}$ \\
\hline & $E_{6}$ & $\mathrm{G}$ & $\mathrm{G}$ & $\mathrm{G}$ & $\mathrm{G}$ & $\mathrm{G}$ & G \\
\hline & $E_{7}$ & $\mathrm{G}$ & $\mathrm{G}$ & G & MG & $\mathrm{P}$ & $\mathrm{P}$ \\
\hline & $E_{8}$ & $\mathrm{VG}$ & $\mathrm{VG}$ & G & $\mathrm{G}$ & MP & $\mathrm{P}$ \\
\hline & $E_{9}$ & VG & VG & MG & MG & $\mathrm{P}$ & MP \\
\hline & $E_{10}$ & $\mathrm{G}$ & $\mathrm{VG}$ & $\mathrm{G}$ & MG & $\mathrm{P}$ & MP \\
\hline \multirow{10}{*}{$K_{5}$} & $E_{1}$ & $\bar{G}$ & $\bar{G}$ & $\mathrm{G}$ & $\mathrm{G}$ & $\bar{G}$ & $\mathrm{~F}$ \\
\hline & $E_{2}$ & G & G & G & $\mathrm{G}$ & G & $\mathrm{G}$ \\
\hline & $E_{3}$ & F & $\mathrm{F}$ & $\mathrm{P}$ & MG & $\mathrm{P}$ & $\mathrm{P}$ \\
\hline & $E_{4}$ & $\mathrm{P}$ & MP & $\mathrm{P}$ & $\mathrm{P}$ & $\mathrm{P}$ & $\mathrm{P}$ \\
\hline & $E_{5}$ & G & $\mathrm{G}$ & $\mathrm{G}$ & $\mathrm{G}$ & G & MG \\
\hline & $E_{6}$ & $\mathrm{G}$ & $\mathrm{G}$ & $\mathrm{G}$ & $\mathrm{G}$ & $\mathrm{G}$ & $\mathrm{G}$ \\
\hline & $E_{7}$ & $\mathrm{G}$ & G & G & $\mathrm{F}$ & MG & $\mathrm{F}$ \\
\hline & $E_{8}$ & $\mathrm{VG}$ & $\mathrm{G}$ & $\mathrm{G}$ & $\mathrm{F}$ & $\mathrm{MG}$ & $\mathrm{F}$ \\
\hline & $E_{9}$ & VG & $\mathrm{G}$ & MG & F & MG & $\mathrm{F}$ \\
\hline & $E_{10}$ & $\mathrm{G}$ & $\mathrm{G}$ & $\mathrm{G}$ & $\mathrm{G}$ & MG & $\mathrm{F}$ \\
\hline \multirow{10}{*}{$K_{6}$} & $E_{1}$ & $\mathrm{G}$ & $\mathrm{G}$ & $\mathrm{G}$ & $\mathrm{G}$ & $\mathrm{G}$ & $\mathrm{F}$ \\
\hline & $E_{2}$ & MG & MG & MG & MG & MG & MG \\
\hline & $E_{3}$ & F & $\mathrm{F}$ & MP & $\mathrm{G}$ & $\mathrm{P}$ & $\mathrm{P}$ \\
\hline & $E_{4}$ & $\mathrm{P}$ & MP & $\mathrm{P}$ & $\mathrm{P}$ & $\mathrm{P}$ & $\mathrm{P}$ \\
\hline & $E_{5}$ & $\mathrm{G}$ & $\mathrm{G}$ & G & $\mathrm{G}$ & G & MG \\
\hline & $E_{6}$ & $\mathrm{G}$ & $\mathrm{G}$ & $\mathrm{G}$ & $\mathrm{G}$ & $\mathrm{G}$ & $\mathrm{G}$ \\
\hline & $E_{7}$ & $\mathrm{G}$ & $\mathrm{G}$ & G & $\mathrm{F}$ & F & $\mathrm{F}$ \\
\hline & $E_{8}$ & VG & $\mathrm{G}$ & $\mathrm{G}$ & MG & F & $\mathrm{F}$ \\
\hline & $E_{9}$ & VG & G & VG & $\mathrm{F}$ & F & $\mathrm{F}$ \\
\hline & $E_{10}$ & VG & VG & $\mathrm{G}$ & MG & MG & $\mathrm{F}$ \\
\hline \multirow{10}{*}{$K_{7}$} & $E_{1}$ & $\bar{G}$ & $\mathrm{G}$ & $\mathrm{G}$ & $\mathrm{G}$ & $\bar{G}$ & $\mathrm{~F}$ \\
\hline & $E_{2}$ & G & $\mathrm{G}$ & $\mathrm{G}$ & G & $\mathrm{G}$ & $\mathrm{G}$ \\
\hline & $E_{3}$ & F & $\mathrm{F}$ & F & $\mathrm{F}$ & VP & MP \\
\hline & $E_{4}$ & $\mathrm{P}$ & MP & $\mathrm{P}$ & $\mathrm{P}$ & $\mathrm{P}$ & $\mathrm{P}$ \\
\hline & $E_{5}$ & $\mathrm{G}$ & $\mathrm{G}$ & $\mathrm{G}$ & $\mathrm{G}$ & G & G \\
\hline & $E_{6}$ & G & $\mathrm{G}$ & $\mathrm{G}$ & $\mathrm{G}$ & $\mathrm{G}$ & $\mathrm{G}$ \\
\hline & $E_{7}$ & $\mathrm{G}$ & $\mathrm{G}$ & $\mathrm{G}$ & $\mathrm{F}$ & F & $\mathrm{F}$ \\
\hline & $E_{8}$ & VG & $\mathrm{G}$ & $\mathrm{G}$ & MG & F & $\mathrm{F}$ \\
\hline & $E_{9}$ & $\mathrm{G}$ & G & VG & $\mathrm{F}$ & $\mathrm{F}$ & $\mathrm{F}$ \\
\hline & $E_{10}$ & $\mathrm{G}$ & $\mathrm{VG}$ & $\mathrm{G}$ & MG & MG & $\mathrm{F}$ \\
\hline
\end{tabular}

Tablo 6. Objektif kriterler için uzmanların değerlendirme sonuçları

\begin{tabular}{ccccccc}
\hline Kriter no & $A_{1}$ & $A_{2}$ & $A_{3}$ & $A_{4}$ & $A_{5}$ & $A_{6}$ \\
\hline$K_{8}$ & 3 & 2 & 2 & 1 & 1 & 3 \\
$K_{9}$ & 1 & 1 & 1 & 1 & 1 & 1 \\
$K_{10}$ & 96 & 100 & 91 & 98 & 100 & 99 \\
\hline
\end{tabular}


Avrupa Bilim ve Teknoloji Dergisi

Tablo 7. Normalize edilmiş değerler

\begin{tabular}{ccccccc}
\hline Kriter no & $A_{1}$ & $A_{2}$ & $A_{3}$ & $A_{4}$ & $A_{5}$ & $A_{6}$ \\
\hline$K_{1}$ & 0,92 & 1,00 & 0,15 & 0,69 & 0,00 & 0,23 \\
$K_{2}$ & 0,80 & 1,00 & 0,33 & 0,85 & 0,08 & 0,00 \\
$K_{3}$ & 1,00 & 0,67 & 0,67 & 0,59 & 0,07 & 0,00 \\
$K_{4}$ & 0,89 & 1,00 & 0,65 & 0,68 & 0,08 & 0,00 \\
$K_{5}$ & 1,00 & 0,89 & 0,64 & 0,49 & 0,38 & 0,00 \\
$K_{6}$ & 1,00 & 0,90 & 0,80 & 0,49 & 0,24 & 0,00 \\
$K_{7}$ & 0,92 & 1,00 & 0,92 & 0,31 & 0,05 & 0,00 \\
$K_{8}$ & 1,00 & 0,50 & 0,50 & 0,00 & 0,00 & 1,00 \\
$K_{9}$ & 1,00 & 1,00 & 1,00 & 1,00 & 1,00 & 1,00 \\
$K_{10}$ & 0,56 & 1,00 & 0,00 & 0,78 & 1,00 & 0,89 \\
\hline
\end{tabular}

Yöntemin üçüncü adımında mutlak değer tablosu oluşturulmuş, sonrasında dördüncü adımda her kriter için referans seri ile mevcut normalize edilmiş seri arasındaki ilişkiyi gösteren gri ilişkisel katsayıları hesaplanmış ve bu değerler Tablo 8'de verilmiştir. Son olarak beşinci adıma göre en yüksek gri ilişkisel katsayılarından oluşan dizi, optimum tedarikçi seçim sırasını oluşturmuştur. Her tedarikçinin gri ilişkisel notu Tablo 9'da gösterilmektedir.

Elde edilen sonuçlar incelendiğinde, en iyi tedarikçi $A_{1}$ olmuştur. Alternatifler en iyiden en kötüye sıralandığında, $A_{1}>A_{2}>A_{3}>$ $A_{4}>A_{6}>A_{5}$ sirası elde edilmektedir.

Tablo 8. Gri ilişkisel katsayılar

\begin{tabular}{ccccccc}
\hline Kriter no & $A_{1}$ & $A_{2}$ & $A_{3}$ & $A_{4}$ & $A_{5}$ & $A_{6}$ \\
\hline$K_{1}$ & 0,87 & 1,00 & 0,37 & 0,62 & 0,33 & 0,39 \\
$K_{2}$ & 0,71 & 1,00 & 0,43 & 0,77 & 0,35 & 0,33 \\
$K_{3}$ & 1,00 & 0,60 & 0,60 & 0,55 & 0,35 & 0,33 \\
$K_{4}$ & 0,83 & 1,00 & 0,59 & 0,61 & 0,35 & 0,33 \\
$K_{5}$ & 1,00 & 0,82 & 0,58 & 0,49 & 0,45 & 0,33 \\
$K_{6}$ & 1,00 & 0,84 & 0,72 & 0,50 & 0,40 & 0,33 \\
$K_{7}$ & 0,87 & 1,00 & 0,87 & 0,42 & 0,35 & 0,33 \\
$K_{8}$ & 1,00 & 0,50 & 0,50 & 0,33 & 0,33 & 1,00 \\
$K_{9}$ & 1,00 & 1,00 & 1,00 & 1,00 & 1,00 & 1,00 \\
$K_{10}$ & 0,53 & 1,00 & 0,33 & 0,69 & 1,00 & 0,82 \\
\hline
\end{tabular}

Tablo 9. Gri ilişkisel notlar

\begin{tabular}{ccccccc}
\hline Tedarikçi & $A_{1}$ & $A_{2}$ & $A_{3}$ & $A_{4}$ & $A_{5}$ & $A_{6}$ \\
\hline Puan & 1,100 & 1,095 & 0,748 & 0,748 & 0,613 & 0,652 \\
\hline
\end{tabular}

\subsection{AHP Yöntemi ile Yeşil Tedarikçi Seçimi}

Yeşil tedarikçi seçim problemi için uygulanan AHP sürecindeki ilk adım olan karar hiyerarşisi Şekil 3'de oluşturulmuştur. Sürecin ikinci adımında uzmanlar tarafından yapılan değerlendirmeler kullanılarak Tablo 10'da verilen ikili karşılaştırmalar matrisi belirlenmiştir. Uzmanlar tarafından verilen kararların tutarlılığını kontrol edilmesi için tutarlılık oranı hesaplanmış ve bu değerin \%7 olduğu bulunmuştur. Bu değerin \%10'dan az olması, karar matrisinin yeterince tutarlı olduğunu göstermektedir. Son olarak elde edilen sonuç vektörü Tablo 11'de gösterilmiştir. Alternatif tedarikçiler için $A_{1}>A_{2}>A_{3}>A_{4}>$ $A_{6}>A_{5}$ siralaması elde edilmektedir. GİA ve AHP sıralamalarının benzerliğini tespit etmek üzere Spearman sıra korelasyon katsayısı $(\rho)$ ve Kendall sıra korelasyon katsayısı $(\tau)$ hesaplanmış ve her iki benzerlik katsayısı değerinin bire eşit olduğu bulunmuştur. $\mathrm{Bu}$ elde edilen sıralamaların ile aynı olduğunu göstermektedir. 


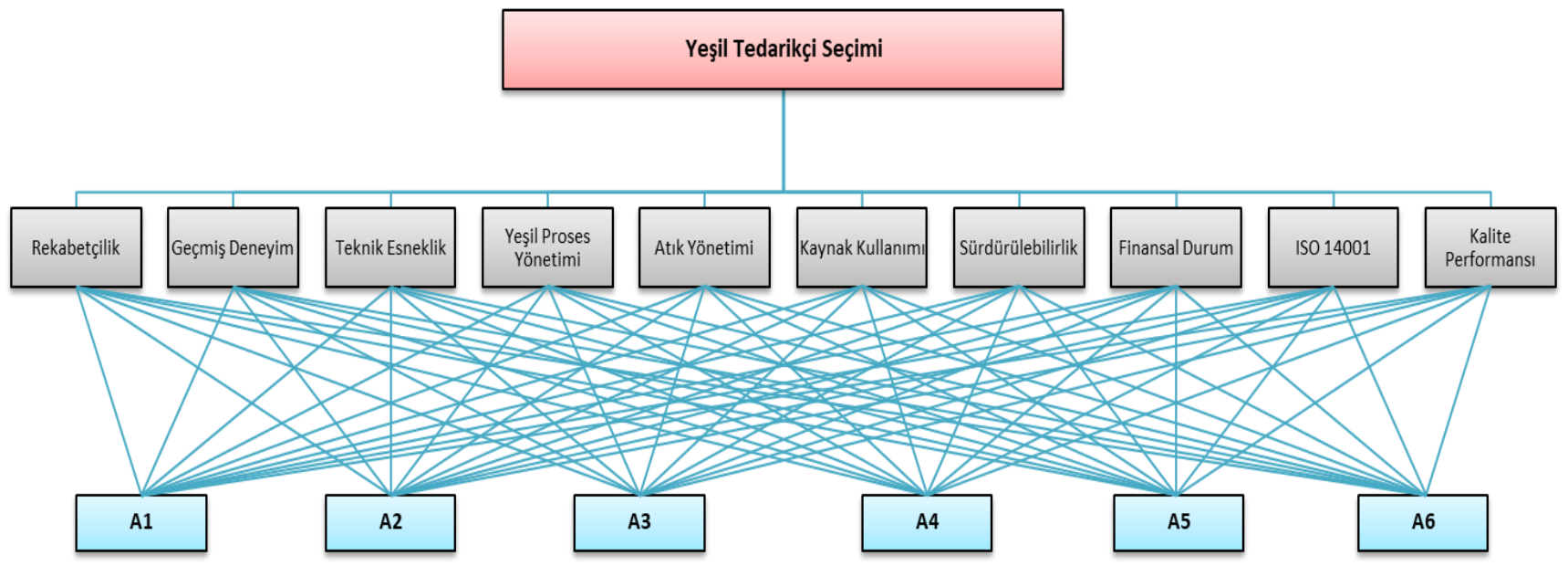

Şekil 3. Yeşil tedarikçi seçimi için analitik hiyerarşi prosesinin yapısı

Tablo 10. İkili karşılaştırmalar matrisi

\begin{tabular}{ccccccccccc}
\hline Kriter no & $K_{1}$ & $K_{2}$ & $K_{3}$ & $K_{4}$ & $K_{5}$ & $K_{6}$ & $K_{7}$ & $K_{8}$ & $K_{9}$ & $K_{10}$ \\
\hline$K_{1}$ & 1,00 & 3,00 & 0,33 & 0,33 & 0,33 & 0,33 & 0,33 & 0,33 & 0,33 & 0,33 \\
$K_{2}$ & 0,33 & 1,00 & 0,33 & 0,20 & 0,20 & 0,20 & 0,20 & 0,14 & 0,20 & 0,20 \\
$K_{3}$ & 3,00 & 3,00 & 1,00 & 0,33 & 0,33 & 0,33 & 0,33 & 0,33 & 0,33 & 0,50 \\
$K_{4}$ & 3,00 & 5,00 & 3,00 & 1,00 & 2,00 & 2,00 & 2,00 & 0,50 & 2,00 & 2,00 \\
$K_{5}$ & 3,00 & 5,00 & 3,00 & 0,50 & 1,00 & 2,00 & 2,00 & 0,50 & 2,00 & 2,00 \\
$K_{6}$ & 3,00 & 5,00 & 3,00 & 0,50 & 0,50 & 1,00 & 2,00 & 0,50 & 2,00 & 2,00 \\
$K_{7}$ & 3,00 & 5,00 & 3,00 & 0,50 & 0,50 & 0,50 & 1,00 & 0,50 & 2,00 & 2,00 \\
$K_{8}$ & 3,00 & 7,00 & 3,00 & 2,00 & 2,00 & 2,00 & 2,00 & 1,00 & 3,00 & 2,00 \\
$K_{9}$ & 3,00 & 5,00 & 3,00 & 0,50 & 0,50 & 0,50 & 0,50 & 0,33 & 1,00 & 2,00 \\
$K_{10}$ & 3,00 & 5,00 & 2,00 & 0,50 & 0,50 & 0,50 & 0,50 & 0,50 & 0,50 & 1,00 \\
\hline
\end{tabular}

Tablo 11. AHP yöntemi sonuçları

\begin{tabular}{lcccccc}
\hline Tedarikçi & $A_{1}$ & $A_{2}$ & $A_{3}$ & $A_{4}$ & $A_{5}$ & $A_{6}$ \\
\hline Puan & 0,283 & 0,269 & 0,143 & 0,119 & 0,077 & 0,109 \\
\hline
\end{tabular}

\section{Duyarlılık Analizi ve Sonuçlar}

Duyarlılık analizi ile girdi değerleri değiştirilerek karar üzerindeki etkilerini değerlendirilebilmektedir (Shen vd., 2013; Haeri ve Rezaei, 2019). GİA yöntemiyle elde edilmiş sonuçların farklı senaryolar üzerinde oluşan etkileri görmek için duyarlılık analizi uygulanmıştır. Tablo 12'de görüleceği gibi altı farklı senaryo ile duyarlılık analizi yapılmıştır. İlk üç senaryoda bazı kriterlerin dikkate almanın etkisini incelemek üzere kriter kümesinde değişiklik yapılmış ve tüm uzmanların verdiği cevaplar değerlendirmelerde dikkate alınmıştır. Senaryo 1'de sadece çevre kriterleri tedarik seçiminde dikkate alınmıştır. Elde edilen sonuçlar incelendiğinde, en iyi tedarikçi 0,938 gri ilişkisel notu ile $A_{1}$ olmuştur. Senaryo 2 için tüm uzmanların sadece fiyat ve kalite kriterlerine verdikleri cevaplar ve gri sayı karşılıkları işleme alınmıştır. Bu senaryo için iyi tedarikçi 0,833 gri ilişkisel notu ile e-ISSN: 2148-2683
$A_{2}$ olmuştur. Senaryo 3 için çevre kriterleri dışındaki tüm kriterler senaryoya dâhil edilmiştir. Elde edilen sonuçlar incelendiğinde, en iyi tedarikçi 0,822 gri ilişkisel notu ile $A_{1}$ olmuştur.

Son üç senaryoda ise uzmanların etkisini görebilmek için uzmanlar kümesinde değişiklik yapılmıştır ve başlangıçta kullanılan tüm kriterler kümesi dikkate alınmıştır. Senaryo 4 için ilk beş uzmanın sonuçları senaryoya dâhil edilmiştir. Elde edilen sonuçlar incelendiğinde, en iyi tedarikçi 0,822 gri ilişkisel notu ile $A_{4}$ olmuştur. Senaryo 5 için son beş uzmanın sonuçları senaryoya dâhil edilmiştir. Elde edilen sonuçlar incelendiğinde, en iyi tedarikçi 0,94 gri ilişkisel notu ile $A_{1}$ olmuştur. Senaryo 6'da, tedarikçi seçimine olan etkisini belirleyebilmek için uzmanlara öncelik değerleri verilmiştir. $E_{2}$ uzmanı için 0,3 etki puanına, diğer uzmanların ise eşit etkiye sahip olduğu varsayılmıştır. Elde 
edilen sonuçlar incelendiğinde, en iyi tedarikçi 0,897 gri ilişkisel notu ile $A_{1}$ olmuştur.

Her bir senaryoda tedarikçilerin aldığı gri ilişkisel not, elde edilen sıralama sonuçları ve sıra korelasyon katsayı değerleri Tablo 13 'de özetlenmiştir. Elde edilen sonuçlara göre, Senaryo 2 ve Senaryo 4 zayıf korelasyona sahip sıralamalardır. Senaryo 2'de uygulanan klasik tedarikçi seçimi kriterleri, olması gereken tedarikçiden farklı bir tedarikçiye seçim yapılmasına neden olmuştur. Bir diğer önemli sonuç ise sürece dâhil edilen uzmanların etkisidir. Senaryo 4 ile elde edilen sonuca göre, mevcut çözüm ve diğer senaryolarda 3 . veya 4. sirada yer alan $A_{4}$ tedarikçisi, bu senaryo ile en iyi tedarikçi olarak yer almıştır. Tedarikçilerin senaryolar bazında yer aldıkları sıralama sonuçları Şekil 4'de gösterilmektedir.

Tablo 12. Senaryolar

\begin{tabular}{cll}
\hline Senaryolar & Karar kriterleri & Uzmanlar (ağırlık) \\
\hline Senaryo 1 & Sadece çevre kriterleri & $E_{1}, E_{2}, E_{3}, E_{4}, E_{5}, E_{6}, E_{7}, E_{8}, E_{9}, E_{10}$ \\
Senaryo 2 & Sadece fiyat ve kalite & $E_{1}, E_{2}, E_{3}, E_{4}, E_{5}, E_{6}, E_{7}, E_{8}, E_{9}, E_{10}$ \\
Senaryo 3 & Çevre kriterleri hariç diğer kriterler & $E_{1}, E_{2}, E_{3}, E_{4}, E_{5}, E_{6}, E_{7}, E_{8}, E_{9}, E_{10}$ \\
Senaryo 4 & Tüm kriterler & $E_{1}, E_{2}, E_{3}, E_{4}, E_{5}$ \\
Senaryo 5 & Tüm kriterler & $E_{6}, E_{7}, E_{8}, E_{9}, E_{10}$ \\
Senaryo 6 & Tüm kriterler & $E_{2}(0,3)$ \\
& & $E_{1}, E_{3}, E_{4}, E_{5}, E_{6}, E_{7}, E_{8}, E_{9}, E_{10}($ eşit $)$ \\
\hline
\end{tabular}

Tablo 13. Senaryolar için gri ilişkisel notlar, sıralama ve korelasyon sonuçları

\begin{tabular}{lccccccccc}
\hline \multirow{2}{*}{ Senaryolar } & \multicolumn{6}{c}{ Gri ilişkisel notları } & Suralama sonucu & $\rho$ & $\tau$ \\
\cline { 2 - 6 } & $A_{1}$ & $A_{2}$ & $A_{3}$ & $A_{4}$ & $A_{5}$ & $A_{6}$ & & & \\
\hline Senaryo 1 & 0,938 & 0,932 & 0,751 & 0,604 & 0,508 & 0,467 & $A_{1}>A_{2}>A_{3}>A_{4}>A_{5}>A_{6}$ & 0,943 & 0,867 \\
Senaryo 2 & 0,799 & 0,833 & 0,402 & 0,548 & 0,556 & 0,737 & $A_{2}>A_{1}>A_{6}>A_{5}>A_{4}>A_{3}$ & 0,429 & 0,200 \\
Senaryo 3 & 0,822 & 0,820 & 0,446 & 0,593 & 0,474 & 0,576 & $A_{1}>A_{2}>A_{4}>A_{6}>A_{5}>A_{3}$ & 0,714 & 0,600 \\
Senaryo 4 & 0,711 & 0,815 & 0,544 & 0,822 & 0,517 & 0,580 & $A_{4}>A_{2}>A_{1}>A_{6}>A_{3}>A_{5}$ & 0,257 & 0,067 \\
Senaryo 5 & 0,940 & 0,820 & 0,646 & 0,524 & 0,515 & 0,516 & $A_{1}>A_{2}>A_{3}>A_{4}>A_{6}>A_{5}$ & 1 & 1 \\
Senaryo 6 & 0,897 & 0,851 & 0,603 & 0,613 & 0,501 & 0,530 & $A_{1}>A_{2}>A_{4}>A_{3}>A_{6}>A_{5}$ & 0,943 & 0,867 \\
\hline
\end{tabular}

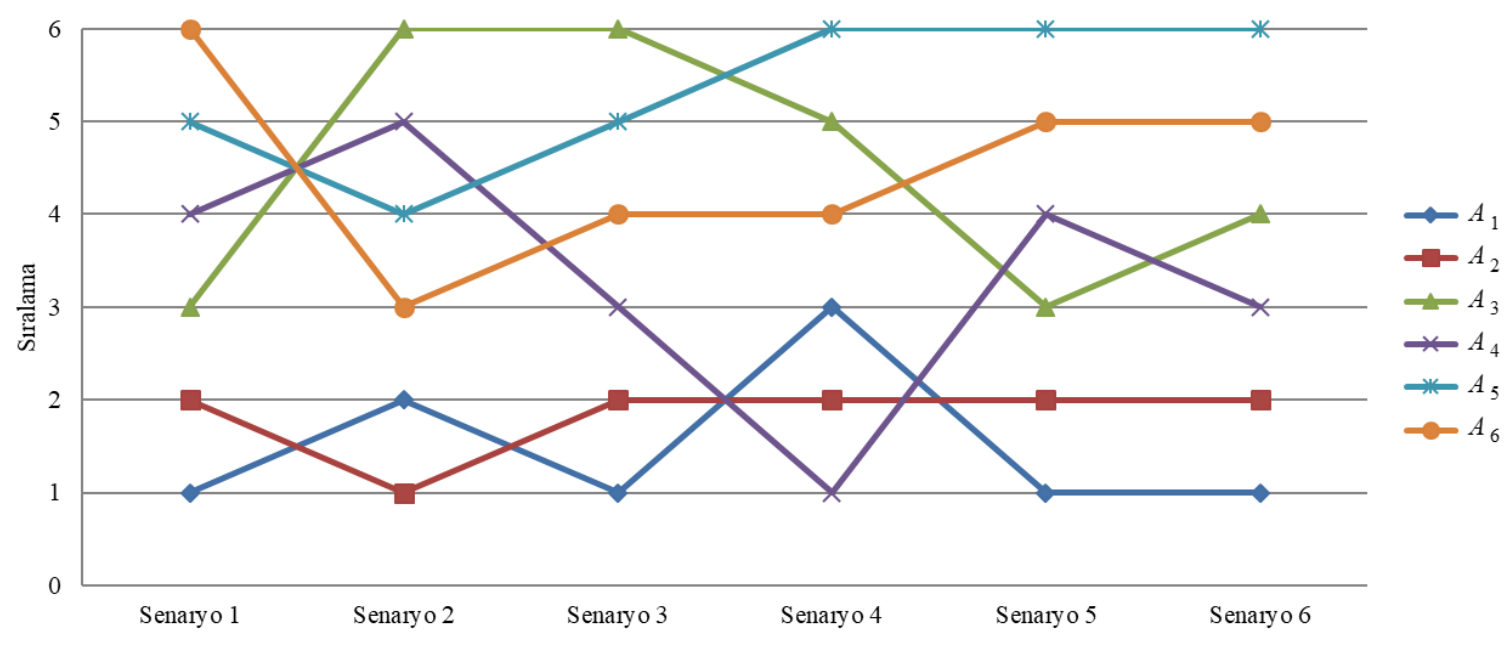

Şekil 4. Senaryo bazında tedarikçi sıralaması 


\section{Tartışma}

Bu çalışmada, klasik tedarikçi seçim yaklaşımlardan farklı olarak yeşil üretim kriteri ana kriterlerden biri olarak çalışmaya dâhil edilerek yeşil tedarikçi seçim problemi ele alınmıştır. Ayrıca bir otomotiv endüstrisi ana sanayi işletmesinin problemi üzerinde uygulama gerçekleştirilmiştir. Otomotiv sektörünün maliyetlerini azaltarak en uygun tercihlerin yapılabilmesi sağlamak üzere bilimsel bir karar süreci gerçekleştirilmiştir. Hem subjektif hem de objektif kriterler seçim sürecinde yer almasından dolayı ÇKKV yöntemlerinden olan GİA yöntemi probleme uygulanmıştır. Elde edilen sonuçlar AHP yöntemi ile elde edilen sonuçlarla karşılaştırılmıştır. Aynı zamanda tedarikçi seçim probleminde karar verici ve kriter kümesinin farklı olmasının seçim süreci sonucunu nasıl etkilediğini belirlemek üzere farklı senaryolar üzerinde duyarlılık analizi gerçekleştirilmiştir. Analiz sonucunda, klasik tedarikçi seçim kriterleri olan fiyat ve kalite ile karar verildiğinde, tedarikçi sıralaması değişebildiği gözlenmiştir. Buradan yeşil olma kriterinin değerlendirme sürecinde yer almasının çok önemli olduğu ve sonuçları etkilediği değerlendirilmiştir. $\mathrm{Bu}$ nedenle sürecin en başında kriterlerin amaca uygun şekilde belirlenmesinin çok önemli olduğu görülmektedir. Senaryolar ile elde edilen bir diğer önemli sonuç ise; sürece dâhil edilen karar vericilerin sayısının ve ağırlıklarının sıralama sonucunu değiştirebilmesidir. Uzmanlık bilgi seviyelerine ve tecrübelerine göre karar vericilere farklı ağırlıklar verilerek daha uygun sıralama sonuçları elde edilebilir.

Tedarikçi seçimlerinde yeşil olma kriterini dikkate alan ana sanayi işletmeleri tedarikçilerini bu yolla yeşil üretim yapmaları konusunda yönlendirmektedir. Böylece tedarikçilerinin de üretim süreçlerinde çevresel etkileri azaltmasını ve bu konulardaki performanslarını iyileştirmelerini sağlamış olacaklardır. Kısaca tedarikçilerinin de sürdürülebilirlik kavramı ile üretim yapmalarına destek olacaklardır.

Gelecekte yapılacak çalışmalarda, önerilen çözüm süreci aynı veya farklı sektörlerdeki işletmelerin tedarikçi seçim süreçlerinde kullanılabilir. Ayrıca belirlenen amaçlara uygun olarak farklı kriter kümeleri tercih edilebilir. Karar vericilerin sürece katkıları da uzmanlık seviyelerine ve tecrübelerine göre farklı şekilde belirlenebilir.

\section{Teşekkür}

$\mathrm{Bu}$ çalışmaya gösterdikleri değerli ilgi ve katkıları için uygulamanın gerçekleştirildiği otomotiv ana sanayi işletmesi çalışanlarına ve yöneticilerine sonsuz teşekkürlerimizi sunarız.

\section{Kaynakça}

Albayrak, E., \& Erensal, Y. C. (2004). Using analytic hierarchy process (AHP) to improve human performance: An application of multiple criteria decision making problem. Journal of Intelligent Manufacturing, 15(4), 491-503.

Awasthi, A., \& Kannan, G. (2016). Green supplier development program selection using NGT and VIKOR under fuzzy environment. Computers \& Industrial Engineering, 91, 100-108.

Babbar, C., \& Amin, S. H. (2018). A multi-objective mathematical model integrating environmental concerns for supplier selection and order allocation based on fuzzy QFD in beverages industry. Expert Systems with Applications, 92, 27-38.

Banaeian, N., Mobli, H., Fahimnia, B., Nielsen, I. E., \& Omid, M. (2018). Green supplier selection using fuzzy group decision making methods: A case study from the agri-food industry. Computers \& Operations Research, 89, 337-347.

Büyüközkan, G. (2012). An integrated fuzzy multi-criteria group decision-making approach for green supplier evaluation. International Journal of Production Research, 50(11), 28922909.

Cao, Q., Wu, J., \& Liang, C. (2015). An intuitionsitic fuzzy judgement matrix and TOPSIS integrated multi-criteria decision making method for green supplier selection. Journal of Intelligent \& Fuzzy Systems, 28(1), 117-126.

Chan, J. W. (2008). Product end-of-life options selection: grey relational analysis approach. International Journal of Production Research, 46(11), 2889-2912.

Dağdeviren, M. (2008). Decision making in equipment selection: an integrated approach with AHP and PROMETHEE. Journal of Intelligent Manufacturing, 19(4), 397-406.

Dweiri, F., Kumar, S., Khan, S. A., \& Jain, V. (2016). Designing an integrated AHP based decision support system for supplier selection in automotive industry. Expert Systems with Applications, 62, 273-283.

Fallahpour, A., Olugu, E. U., Musa, S. N., Khezrimotlagh, D., \& Wong, K. Y. (2016). An integrated model for green supplier selection under fuzzy environment: application of data envelopment analysis and genetic programming approach. Neural Computing and Applications, 27(3), 707-725.

Genovese, A., Lenny Koh, S. C., Bruno, G., \& Esposito, E. (2013). Greener supplier selection: state of the art and some empirical evidence. International Journal of Production Research, 51(10), 2868-2886.

Govindan, K., Rajendran, S., Sarkis, J., \& Murugesan, P. (2015). Multi criteria decision making approaches for green supplier evaluation and selection: A literature review. Journal of Cleaner Production, 98, 66-83.

Govindan, K., Kadziński, M., \& Sivakumar, R. (2017). Application of a novel PROMETHEE-based method for construction of a group compromise ranking to prioritization of green suppliers in food supply chain. Omega, 71, 129-145.

Grisi, R. M., Guerra, L., \& Naviglio, G. (2010). Supplier performance evaluation for green supply chain management, In P. Taticchi, Business Performance Measurement and Management (pp. 149163), Berlin, Heidelberg: Springer.

Gupta, H., \& Barua, M. K. (2017). Supplier selection among SMEs on the basis of their green innovation ability using BWM and fuzzy TOPSIS. Journal of Cleaner Production, 152, 242-258.

Gupta, S., Soni, U., \& Kumar, G. (2019). Green supplier selection using multi-criterion decision making under fuzzy environment: A case study in automotive industry. Computers \& Industrial Engineering, 136, 663-680.

Haeri, S. A. S., \& Rezaei, J. (2019). A grey-based green supplier selection model for uncertain environments. Journal of Cleaner Production, 221, 768-784.

Hamdan, S., \& Cheaitou, A. (2017). Dynamic green supplier selection and order allocation with quantity discounts and varying supplier availability. Computers \& Industrial Engineering, 110, 573-589.

Hashemi, S. H., Karimi, A., Aghakhani, N., \& Kalantar, P. (2014). A grey-based carbon management model for green supplier selection. Journal of Grey System, 26(2), 124-131.

Hashemi, S. H., Karimi, A., \& Tavana, M. (2015). An integrated green supplier selection approach with analytic network process and improved Grey relational analysis. International Journal of Production Economics, 159, 178-191.

Hsu, C. W., Kuo, T. C., Chen, S. H., \& Hu, A. H. (2013). Using DEMATEL to develop a carbon management model of supplier selection in green supply chain management. Journal of Cleaner Production, 56, 164-172. 
Humphreys, P. K., Wong, Y. K., \& Chan, F. T. S. (2003). Integrating environmental criteria into the supplier selection process. Journal of Materials Processing Technology, 138(1-3), 349-356.

Igarashi, M., de Boer, L., \& Fet, A. M. (2013). What is required for greener supplier selection? A literature review and conceptual model development. Journal of Purchasing and Supply Management, 19(4), 247-263.

IPCC (2014). Climate Change 2014: Mitigation of Climate Change. Contribution of Working Group III to the Fifth Assessment Report of the Intergovernmental Panel on Climate Change. Cambridge University Press, Cambridge, United Kingdom and New York, NY: USA.

Jain, V., Kumar, S., Kumar, A., \& Chandra, C. (2016). An integrated buyer initiated decision-making process for green supplier selection. Journal of Manufacturing Systems, 41, 256-265.

Kahraman, C., Cebeci, U., \& Ulukan, Z. (2003). Multi-criteria supplier selection using fuzzy AHP. Logistics Information Management, 16(6), 382-394.

Kannan, D., de Sousa Jabbour, A. B. L., \& Jabbour, C. J. C. (2014). Selecting green suppliers based on GSCM practices: Using fuzzy TOPSIS applied to a Brazilian electronics company. European Journal of Operational Research, 233(2), 432-447.

Kannan, D., Govindan, K., \& Rajendran, S. (2015). Fuzzy axiomatic design approach based green supplier selection: A case study from Singapore. Journal of Cleaner Production, 96, 194-208.

Kannan, D., Khodaverdi, R., Olfat, L., Jafarian, A., \& Diabat, A. (2013). Integrated fuzzy multi criteria decision making method and multi-objective programming approach for supplier selection and order allocation in a green supply chain. Journal of Cleaner Production, 47, 355-367.

Kumar, S., Teichman, S., \& Timpernagel, T. (2012). A green supply chain is a requirement for profitability. International Journal of Production Research, 50(5), 1278-1296.

Kuo, R. J., Wang, Y. C., \& Tien, F. C. (2010). Integration of artificial neural network and MADA methods for green supplier selection. Journal of Cleaner Production, 18(12), 1161-1170.

Kuo, Y., Yang, T., \& Huang, G. W. (2008). The use of grey relational analysis in solving multiple attribute decision-making problems. Computers \& Industrial Engineering, 55(1), 80-93.

Lee, A. H., Kang, H. Y., Hsu, C. F., \& Hung, H. C. (2009). A green supplier selection model for high-tech industry. Expert Systems with Applications, 36(4), 7917-7927.

Li, G. D., Yamaguchi, D., \& Nagai, M. (2008). A grey-based rough decision-making approach to supplier selection. The International Journal of Advanced Manufacturing Technology, 36(9-10), 1032.

Liu, S., \& Lin, Y. (2010). Introduction to grey systems theory. In Grey Systems. Understanding Complex Systems, vol 68. (pp. 1-18). Berlin, Heidelberg: Springer.

Lu, L. Y., Wu, C. H., \& Kuo, T. C. (2007). Environmental principles applicable to green supplier evaluation by using multi-objective decision analysis. International Journal of Production Research, 45(18-19), 4317-4331.

Montoya-Torres, J. R., Gutierrez-Franco, E., \& Blanco, E. E. (2015). Conceptual framework for measuring carbon footprint in supply chains. Production Planning \& Control, 26(4), 265-279.

Pitchipoo, P., Venkumar, P., \& Rajakarunakaran, S. (2015). Grey decision model for supplier evaluation and selection in process industry: A comparative perspective. The International Journal of Advanced Manufacturing Technology, 76(9-12), 2059-2069.

Qin, J., Liu, X., \& Pedrycz, W. (2017). An extended TODIM multicriteria group decision making method for green supplier selection in interval type-2 fuzzy environment. European Journal of Operational Research, 258(2), 626-638.

Rajesh, R., \& Ravi, V. (2015). Supplier selection in resilient supply chains: a grey relational analysis approach. Journal of Cleaner Production, 86, 343-359.

Roshandel, J., Miri-Nargesi, S. S., \& Hatami-Shirkouhi, L. (2013). Evaluating and selecting the supplier in detergent production industry using hierarchical fuzzy TOPSIS. Applied Mathematical Modelling, 37(24), 10170-10181.

Saaty, T. L. (1977). A scaling method for priorities in hierarchical structures. Journal of Mathematical Psychology, 15(3), 234-281.

Saaty, T. L. (1990). How to make a decision: the analytic hierarchy process. European Journal of Operational Research, 48(1), 926.

Shen, L., Olfat, L., Govindan, K., Khodaverdi, R., \& Diabat, A. (2013). A fuzzy multi criteria approach for evaluating green supplier's performance in green supply chain with linguistic preferences. Resources, Conservation and Recycling, 74, 170179.

Şişman, B. (2016). Bulanık MOORA yöntemi kullanılarak yeşil tedarikçi geliştirme programlarının seçimi ve değerlendirilmesi. Journal of Yaşar University, 11(44), 302-315.

Tsai, W. H., \& Hung, S. J. (2009). A fuzzy goal programming approach for green supply chain optimisation under activitybased costing and performance evaluation with a value-chain structure. International Journal of Production Research, 47(18), 4991-5017.

Tsui, C. W., \& Wen, U. P. (2014). A hybrid multiple criteria group decision-making approach for green supplier selection in the TFT-LCD industry. Mathematical Problems in Engineering, 2014.

Tuzkaya, G., Ozgen, A., Ozgen, D., \& Tuzkaya, U. R. (2009). Environmental performance evaluation of suppliers: A hybrid fuzzy multi-criteria decision approach. International Journal of Environmental Science \& Technology, 6(3), 477-490.

Wan, S. P., Zou, W. C., Zhong, L. G., \& Dong, J. Y. (2020). Some new information measures for hesitant fuzzy PROMETHEE method and application to green supplier selection. Soft Computing, 24, 9179-9203.

Wang Chen, H. M., Chou, S. Y., Luu, Q. D., \& Yu, T. H. K. (2016). A fuzzy MCDM approach for green supplier selection from the economic and environmental aspects. Mathematical Problems in Engineering, 2016.

Wu, H. H. (2002). A comparative study of using grey relational analysis in multiple attribute decision making problems. Quality Engineering, 15(2), 209-217.

Yang, C. C., \& Chen, B. S. (2006). Supplier selection using combined analytical hierarchy process and grey relational analysis. Journal of Manufacturing Technology Management, 17(7), 926-941.

Yazdani, M., Chatterjee, P., Zavadskas, E. K., \& Zolfani, S. H. (2017). Integrated QFD-MCDM framework for green supplier selection. Journal of Cleaner Production, 142, 3728-3740.

Yeh, W. C., \& Chuang, M. C. (2011). Using multi-objective genetic algorithm for partner selection in green supply chain problems. Expert Systems with Applications, 38(4), 4244-4253. 